\title{
Hypoglycaemia induces decreased islet blood perfusion mediated by the central nervous system in normal and Type 2 diabetic GK rats
}

\author{
P.-O. Carlsson' ${ }^{1,}$, C. Berne ${ }^{2}$, C.-G. Östenson ${ }^{3}$, A. Andersson'1, L. Jansson'1 \\ ${ }^{1}$ Department of Medical Cell Biology, Biomedical Centre, Uppsala, Sweden \\ ${ }^{2}$ Department of Medical Sciences, Uppsala University, Uppsala, Sweden \\ ${ }^{3}$ Department of Endocrinology, Karolinska Institute and Hospital, Stockholm, Sweden
}

\section{Abstract}

Aims/hypothesis. The aim of this study was to evaluate the effects of induced hypoglycaemia on pancreatic-islet blood flow in normal rats and in the GK rat, an animal model of Type 2 diabetes which normally has an increased islet blood perfusion.

Methods. A 50\% reduction in blood glucose concentrations was achieved by intravenous administration of a rapidly acting insulin (15 IU/kg body weight). Blood flows were measured by a non-radioactive microsphere technique.

Results. A pronounced decrease in islet blood flow was observed in all animals, but preferentially in the Type 2 diabetic GK rats. When a similar dose of insulin was given to whole-pancreas transplanted rats only islet blood flow in the native pancreas was decreased, whereas that of the transplanted, i.e. denervated, pancreas was unchanged. Administration of 2-deoxy-Dglucose, which induces intracellular glucopenia espe- cially in neurons, also decreased islet blood flow despite a systemic hyperglycaemia.

Conclusion/interpretation. Hypoglycaemia leads to a preferential decrease in pancreatic-islet blood perfusion. The effect is probably mediated by the central nervous system, since 2-deoxy D-glucose-induced neuronal glucopenia caused a similar decrease in blood flow. The effects of islet blood flow are not likely to be mediated by nervous stimulation of the adrenal glands, with an associated release of catecholamines, because the transplanted pancreas was not affected by hypoglycaemia. The decreased islet blood perfusion could possibly diminish the output of insulin from the islets, thereby preventing a further decrease in blood glucose concentrations. [Diabetologia (2003) 46:1124-1130]

Keywords Blood flow, 2-deoxy glucose, hypoglycaemia, insulin, pancreas, pancreatic islets
Pancreatic islet blood flow is regulated through complex interactions between locally produced factors, gastrointestinal neuropeptides and influences from the nervous system [1]. Although a dissociation can occur $[2,3]$, the degree of islet blood perfusion is normally

Received: 11 February 2003 / Revised: 9 April 2003

Published online: 26 June 2003

C) Springer-Verlag 2003

Corresponding author: P.-O. Carlsson, Department of Medical Cell Biology, Biomedical Centre, Box 571, 75123 Uppsala, Sweden

E-mail: Per-Ola.Carlsson@medcellbiol.uu.se

Abbreviations: GK, Goto-Kakizaki. closely correlated to the metabolic demands and to the need for insulin secretion [1].

Ambient blood glucose concentration seems to be the most important single factor for the control of islet blood perfusion. Acute hyperglycaemia increases islet blood flow mainly by acting on glucose receptors within the brain, intestines and liver, which mediate effects on the pancreatic islets via the nervous system $[4,5,6,7]$. Animals with chronic hyperglycaemia, experimental-induced or spontaneous models of Type 2 diabetes, have a strongly increased islet blood flow $[8,9,10,11,12]$. At least in Type 2 diabetic GK rats, this islet blood hyperperfusion seems glucosedependent [13] and related to increased vagal nerve activity [11]. 
The effects of hypoglycaemia on islet blood perfusion have been investigated, but have yielded conflicting results. In an early study to induce hypoglycaemia, exogenous administration of insulin increased islet blood flow [14], whereas a more recent study found no effects on islet blood perfusion [15]. Tolbutamide in doses inducing hypoglycaemia has increased islet blood flow [16], whereas mild hypoglycaemia induced by starvation decreased islet blood perfusion [2]. Some of these discrepancies can be explained by the vasodilatory properties of insulin [17, 18, 19] and tolbutamide [20, 21]. We investigated the effects of insulin-induced hypoglycaemia and of 2-deoxy glucose, which inhibits neuronal uptake of glucose and thereby induces a neuronal glucopenia $[22,23]$ on islet blood flow. The importance of the nervous system for the occurrence of changes in hypoglycaemia induced by islet blood flow was further evaluated by studies on denervated whole-pancreas transplants. Moreover, GK rats and their $\mathrm{F}_{1}$-hybrids were used as a model to investigate the influence of hypoglycaemia on islet blood flow in Type 2 diabetes.

\section{Materials and methods}

Animals. Male Sprague-Dawley rats, weighing 325 to $350 \mathrm{~g}$, were obtained from a local breeding colony (Biomedical Centre, Uppsala, Sweden). Inbred Wistar-Furth rats, weighing $300 \mathrm{~g}$, were purchased from Möllegaard (Ry, Denmark). Wistar rats, weighing 300 to $350 \mathrm{~g}$ were obtained from B\&K (Sollentuna, Sweden), whereas Goto-Kakizaki (GK) and hybrids between GK and Wistar rats were obtained from a local breeding colony (Department of Endocrinology, Karolinska Institute, Stockholm, Sweden) established in 1988 with breeding couples from the colony at the Tohoku University School of Medicine (Sendai, Japan). The GK strain originated from normal Wistar rats, which were bred using glucose intolerance as a selection index [24, 25, 26]. All animals had free access to tap water and pelleted rat food. All experiments were approved by the local animal ethics committee for Uppsala University and followed the "Principles of laboratory animal care (NIH publication no. 85-23, revised 1985).

Blood flow measurements after insulin administration. The rats were anesthetized with an intraperitoneal injection of pentobarbital $(60 \mathrm{mg} / \mathrm{kg}$; Mebumal; Apoteksbolaget, Umeå, Sweden), heparinized and placed on an operating table maintained at body temperature. Polyethylene catheters were inserted into the ascending aorta and the left femoral artery. The former catheter was connected to a pressure transducer (PDCR 75/1; Druck, Groby, UK). When the blood pressure had remained stable for at least $15 \mathrm{~min}$ an intravenous injection of $15 \mathrm{IU} / \mathrm{kg}$ of insulin (Actrapid Human; Novo Nordisk, Bagsvaerd, Denmark) or the corresponding volume $(0.2 \mathrm{ml})$ of diluting medium (Novo Nordisk) was given. Then regional blood flow was measured by using a non-radioactive microsphere technique [27] 30 min later.

Arterial blood was collected from the carotid catheter to measure blood glucose and serum insulin concentrations as given below. The animals were then killed, and the pancreas and adrenal glands were removed, weighed and treated with a freeze-thawing technique, which visualised the pancreatic islets and microspheres [28]. In the Sprague-Dawley rats also approximately $100 \mathrm{mg}$ each of the duodenum (around the papilla), ileum (termi- nal part), colon (descending part), liver (anterior lobe) and a slice from the mid-region of the right kidney encompassing both cortex and medulla ( 150-200 mg of each) were removed and treated in the same way. The microspheres in organs and arterial blood were then counted in a microscope (Wild M3Z; Wild Heerbrugg, Heerbrugg, Switzerland). The blood flow values were calculated according to the formula: $\mathrm{Q}_{\mathrm{org}}=\mathrm{Q}_{\text {ref }} \times \mathrm{N}_{\text {org }} / \mathrm{N}_{\text {ref }}$ where $\mathrm{Q}_{\text {org }}$ is organ blood flow ( $\left.\mathrm{ml} / \mathrm{min}\right), \mathrm{Q}_{\text {ref }}$ is withdrawal rate of the reference sample, $\mathrm{N}_{\text {org }}$ is number of microspheres present in the organ and $\mathrm{N}_{\text {ref }}$ is the number of microspheres in the reference sample. A difference of less than $10 \%$ in the blood flow to the adrenal glands was used to confirm that the microspheres were adequately dispersed in the circulation.

Blood flow measurements after administration of 2-deoxy glucose. The surgical preparation was carried out as described above. 2-deoxy glucose (Sigma) was dissolved in saline, and then administered intravenously ( $3 \mathrm{mmol} / \mathrm{kg}$ body weight) $5 \mathrm{~min}$ before the blood flow measurements. Control animals were given the same volume ( $2 \mathrm{ml} / \mathrm{kg}$ body weight) of saline alone. Blood flow was measured with the microsphere technique referred to above. Only the blood perfusion to the whole pancreas, islets and the adrenal glands was assessed in these animals.

Pancreatico-duodenal transplantations. This procedure has been described in detail elsewhere [29]. The animals were surgically prepared to measure blood flow 14 days after transplantation. An intravenous injection of human insulin (15 IU $/ \mathrm{kg}$; Actrapid Human; Novo) or a similar volume of diluting medium (Novo) was then given. After $30 \mathrm{~min}$ the blood flow values to the whole native and transplanted pancreata, the islets in both glands and the native and transplanted duodenum were measured with the microsphere technique.

Measurements of blood glucose and serum insulin concentrations. Blood glucose concentrations were measured with test reagent strips (Medisense; Baxter Travenol, Deerfield, Ill., USA). Serum insulin concentrations were measured with radioimmunoassay (Insulin RIA Kit; Pharmacia-Upjohn, Uppsala, Sweden) using a rat insulin standard (Novo).

Statistical calculations. All values are given as means \pm SEM. Probabilities $(p)$ of chance differences were calculated with Students unpaired $t$ test or ANOVA with Fisher's protected least significant difference test. A $p$ value of less than 0.05 was considered to be statistically significant.

\section{Results}

Effects of insulin administration in normal rats. Administration of insulin to Sprague-Dawley rats caused a pronounced decrease in their blood glucose concentrations, which was observable already after $15 \mathrm{~min}$, but was more prominent $30 \mathrm{~min}$ after the insulin injection (Table 1). There were no changes in the mean arterial blood pressure in any of the rats (Table 1). Insulin administration only tended to decrease blood flow in the whole pancreas (NS, Table 1), but substantially reduced islet blood flow (Fig. 1). The fraction of whole pancreatic blood flow diverted through the islets decreased from approximately $9 \%$ to $5 \%$. Insulin administration induced an increase in adrenal and arterial hepatic blood flow, but did not change the blood perfusion of the other examined organs (Table 2). 


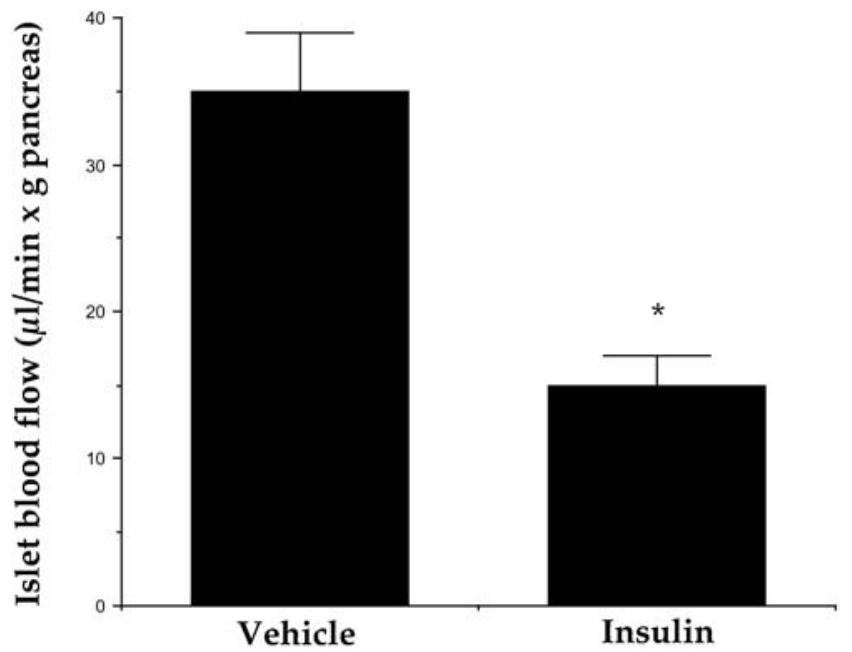

Fig. 1. Islet blood flow in Sprague-Dawley rats $30 \mathrm{~min}$ after an intravenous injection of $0.2 \mathrm{ml}$ of a rapidly acting insulin $(15 \mathrm{IU} / \mathrm{kg})$ or vehicle. Values are given as means \pm SEM. *denotes $p<0.01$ when compared to vehicle-treated rats

Table 1. Effects of insulin on blood glucose concentrations, mean arterial blood pressure and pancreatic blood flow in Sprague-Dawley rats

\begin{tabular}{lll}
\hline Substance given & Vehicle & Insulin \\
\hline $\begin{array}{l}\text { No of experiments } \\
\text { Blood glucose concentration }\end{array}$ & 10 & 9 \\
$\quad(\mathrm{mmol} / \mathrm{l})$ & $5.8 \pm 0.05$ & $2.5 \pm 0.3^{\mathrm{a}}$ \\
$\begin{array}{l}\text { Mean arterial blood pressure } \\
\quad(\mathrm{mm} \mathrm{Hg})\end{array}$ & $104 \pm 3$ & $111 \pm 9$ \\
$\begin{array}{l}\text { Total pancreatic blood flow } \\
\quad(\mathrm{ml} / \mathrm{min} \times \mathrm{g} \text { pancreas })\end{array}$ & $0.47 \pm 0.08$ & $0.34 \pm 0.05$ \\
\hline
\end{tabular}

Values are given as means \pm SEM. adenotes $p<0.001$ when compared to vehicle-treated rats

Table 2. Effects of insulin on organ blood flow in Sprague-Dawley rats. All values are given in $\mathrm{ml} / \mathrm{min} \times \mathrm{g}$ organ wet weight

\begin{tabular}{lcl}
\hline Substance given & Vehicle & Insulin \\
\hline No of experiments & 10 & 9 \\
Duodenal blood flow & $0.97 \pm 0.12$ & $0.76 \pm 0.16$ \\
Ileal blood flow & $0.42 \pm 0.05$ & $0.46 \pm 0.04$ \\
Colonic blood flow & $0.26 \pm 0.04$ & $0.25 \pm 0.05$ \\
Arterial hepatic blood flow & $0.07 \pm 0.02$ & $0.18 \pm 0.04 \mathrm{~b}$ \\
Renal blood flow & $3.34 \pm 0.48$ & $2.43 \pm 0.26$ \\
Adrenal blood flow & $1.84 \pm 0.26$ & $3.04 \pm 0.45^{\mathrm{a}}$ \\
\hline
\end{tabular}

Values are given as means \pm SEM. ${ }^{\text {adenotes } p<0.05 \text { and }}$ ${ }^{\mathrm{b}} p<0.02$ when compared to vehicle-treated rats

When insulin was given to whole-pancreas transplanted Wistar Furth rats it also induced pronounced hypoglycaemia (Table 3). No effects on the mean arterial blood pressure or the blood perfusion of the native or transplanted pancreas were observed after insulin injection (Table 3 ). Neither could any change in the

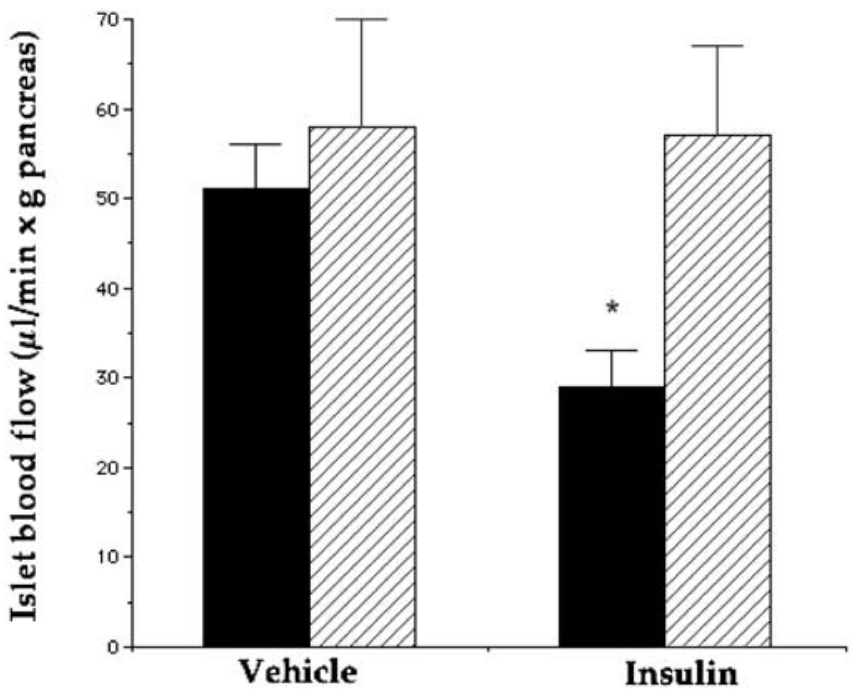

Fig. 2. Islet blood flow in the native (black bars) and transplanted (hatched bars) pancreas of Wistar Furth rats 14 days after a syngeneic pancreaticoduodenal transplantation. The animals were injected intravenously with $0.2 \mathrm{ml}$ of a rapidly acting insulin $(15 \mathrm{IU} / \mathrm{kg})$ or vehicle rats $30 \mathrm{~min}$ before measurements. Values are given as means \pm SEM. *denotes $p<0.01$ when compared to vehicle-treated rats

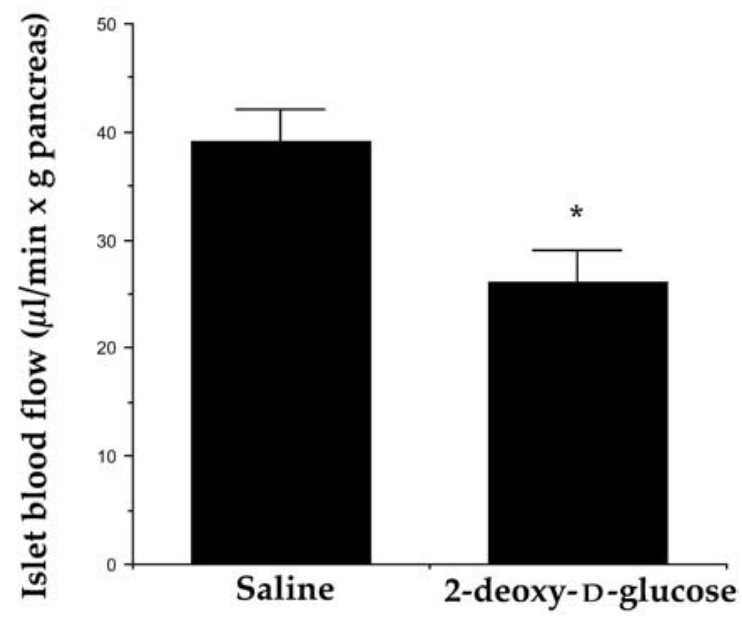

Fig. 3. Islet blood flow in Sprague-Dawley rats 5 min after an intravenous injection of $20 \mathrm{ml} / \mathrm{kg}$ bodyweight of 2-deoxy-Dglucose $(3 \mathrm{mmol} / \mathrm{kg}$ body weight) dissolved in saline or saline alone. Values are given as means \pm SEM. *denotes $p<0.01$ when compared to saline-treated rats

blood perfusion of the native or transplanted duodenum be seen. The islet blood flow, however, was lowered only in the native pancreas but not in the transplanted gland after insulin administration (Fig. 2).

Effects of 2-deoxy glucose in normal rats. Administration of this substance increased blood glucose concentrations (Table 4). No changes in mean arterial blood pressure were seen (Table 4). An increased whole pancreatic blood flow was seen after administration (Table 4), whilst islet blood flow was decreased by approximately $40 \%$ (Fig. 3 ). 
Table 3. Effects of insulin on blood glucose concentrations, mean arterial blood pressure, native pancreatic and transplanted pancreatic blood flow in Wistar-Furth rats 14 days after a syngeneic pancreatico-duodenal transplantation

\begin{tabular}{|c|c|c|c|c|}
\hline \multirow{2}{*}{$\begin{array}{l}\text { Substance given } \\
\text { No of experiments } \\
\text { Pancreas }\end{array}$} & \multicolumn{2}{|l|}{$\begin{array}{l}\text { Vehicle } \\
6\end{array}$} & \multicolumn{2}{|l|}{$\begin{array}{l}\text { Insulin } \\
6\end{array}$} \\
\hline & Native & Transplanted & Native & Transplanted \\
\hline Blood glucose (mmol/l) & $5.5 \pm 0.5$ & & $2.6 \pm 0.3^{\mathrm{a}}$ & \\
\hline Mean arterial blood pressure $(\mathrm{mmHg})$ & $97 \pm 5$ & & $94 \pm 6$ & \\
\hline Pancreatic blood flow & $0.45 \pm 0.10$ & $0.60 \pm 0.12$ & $0.34 \pm 0.07$ & $0.47 \pm 0.14$ \\
\hline
\end{tabular}

Values are given as means \pm SEM. adenotes $p<0.01$ when compared to the vehicle-treated rats

Table 4. Effects of 2-deoxy-D-glucose on blood glucose concentrations, mean arterial blood pressure and pancreatic blood flow in Sprague-Dawley rats

\begin{tabular}{lcc}
\hline Substance given & Saline & 9 \\
No of experiments & 9 & 9 \\
\hline Blood glucose concentration (mmol/l) & $6.3 \pm 0.4$ & $14.4 \pm 0.9^{\mathrm{b}}$ \\
Mean arterial blood pressure (mmHg) & $108 \pm 6$ & $116 \pm 3$ \\
Pancreatic blood flow (ml/min $\times \mathrm{g}$ pancreas) & $0.37 \pm 0.07$ & $0.52 \pm 0.05^{\mathrm{a}}$ \\
\hline
\end{tabular}

Values are means \pm SEM. adenotes $p<0.05$ and ${ }^{\mathrm{b}} p<0.001$ when compared to saline-injected rats

Table 5. Effects of insulin on blood glucose, mean arterial blood pressure and pancreatic blood flow in Wistar, GK or $\mathrm{F}_{1}$-hybrids between GK and Wistar rats

\begin{tabular}{|c|c|c|c|c|c|c|}
\hline $\begin{array}{l}\text { Strain } \\
\text { Substance given } \\
\text { No of experiments }\end{array}$ & $\begin{array}{l}\text { Wistar } \\
\text { Vehicle } \\
6\end{array}$ & $\begin{array}{l}\text { Wistar } \\
\text { Insulin } \\
6\end{array}$ & $\begin{array}{l}\mathrm{F}_{1} \text {-hybrid } \\
\text { Vehicle } \\
6\end{array}$ & $\begin{array}{l}\mathrm{F}_{1} \text {-hybrid } \\
\text { Insulin } \\
6\end{array}$ & $\begin{array}{l}\text { GK } \\
\text { Vehicle } \\
8\end{array}$ & $\begin{array}{l}\text { GK } \\
\text { Insulin } \\
8\end{array}$ \\
\hline Mean arterial blood pressure $(\mathrm{mmHg})$ & $110 \pm 4$ & $115 \pm 6$ & $121 \pm 2$ & $118 \pm 5$ & $113 \pm 7$ & $101 \pm 7$ \\
\hline $\begin{array}{l}\text { Pancreatic blood flow } \\
(\mathrm{ml} / \mathrm{min} \times \mathrm{g} \text { pancreas })\end{array}$ & $0.85 \pm 0.10$ & $0.55 \pm 0.05^{\mathrm{c}}$ & $0.82 \pm 0.12$ & $0.44 \pm 0.08^{c}$ & $1.04 \pm 0.16$ & $0.36 \pm 0.04^{\mathrm{a}, \mathrm{d}}$ \\
\hline
\end{tabular}

Values are given as means \pm SEM. adenotes $p<0.05$ and ${ }^{b} p<0.001$ when compared to the corresponding group of Wistar rats. ${ }^{\mathrm{c}} \mathrm{de}-$ notes $p<0.05$, and ${ }^{\mathrm{d}} p<0.001$ when compared with the corresponding vehicle-treated rats

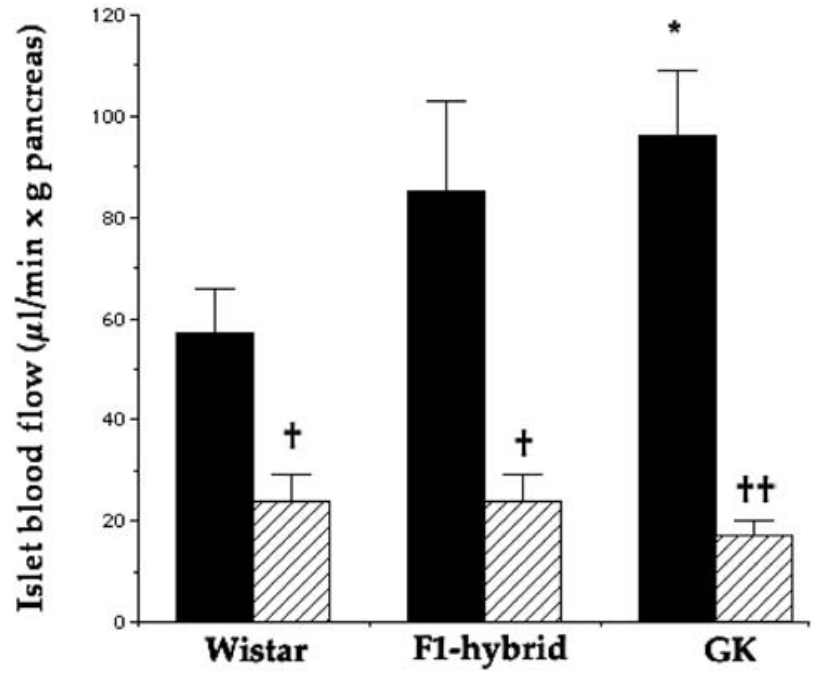

Fig. 4. Islet blood flow in Wistar rats, GK rats and F1-hybrids of GK and Wistar rats 30 min after an intravenous injection of $0.2 \mathrm{ml}$ of a rapidly acting insulin (15 IU/kg; hatched bars) or vehicle (black bars). Values are given as means \pm SEM. *denotes $p<0.05$ when compared to Wistar rats, whereas †denotes $p<0.01$ and ${ }^{\dagger \dagger} p<0.001$ when compared to vehicle-treated rats
Effects of insulin administration in GK rats. Both GK rats and F1-hybrids between GK and Wistar rats had higher blood glucose concentrations, when compared to control Wistar rats (Table 5). Administration of insulin decreased blood glucose concentrations in all animals (Table 5). Mean arterial blood pressure was similar in all animals and was not affected by insulin administration (Table 5). Basal islet blood flow was higher in the GK rats than in the control rats (Fig. 4). Insulin injection decreased whole pancreatic blood flow (Table 5), but preferentially islet blood flow (Fig. 4) in all rats. A more pronounced decrease in islet blood flow was observed in the GK rats (Fig. 4). After insulin administration there were no differences in islet blood perfusion between GK and control rats.

\section{Discussion}

A consistent decrease in pancreatic islet blood flow was observed in all investigated rat strains in re- 
sponse to insulin-induced hypoglycaemia. This is in contrast to previous studies, also using the microsphere technique, where either an increased [14] or an unchanged [15] islet blood flow was recorded. The reasons for the discrepancy between these studies are not known. Compared to most studies on islet blood flow in adult rats [1, 10, 12, 31, 32] one group [14] obtained a considerably lower value $(2 \%$ vs $7-20 \%)$ for the control rats. Such low islet blood flow values have previously only been recorded in very young animals [16, 33, 34]. Another group [15] used an elegant technique with repeated injections of microspheres in conscious rats and showed no influence of insulin-induced hypoglycaemia on islet blood flow. The differences in the results on islet blood flow could therefore be explained by the use of anaesthesia or lack thereof. However, although the technique used with repeated injection of microspheres enables paired observations, it relies on the basic concept that the distribution of a second microsphere injection is not influenced by the first injection. As recently evaluated $[15,35]$, such influence might not occur in untreated animals, although it critically depends on the embolized mass in the body. Occlusion of too many capillary beds after the first injection causes an erroneous increase in both whole pancreatic and islet blood flow as measured by a second microsphere injection [35]. It is therefore not certain that a decrease in islet blood flow is easily detectable with the repeated microsphere technique, especially with a rather high dose of microspheres (400 000 in each injection) [15]. In view of this, as well as the consistency in our findings in different strains of a decreased islet blood flow in conjunction with hypoglycaemia, it is likely that insulin-induced hypoglycaemia causes a reduction in islet blood perfusion.

In previous work $[4,5,6]$, changes in glucose-dependent islet blood flow preferentially depend on nerve-mediated signals. Therefore, the islet blood flow response to hypoglycaemia was further evaluated by administration of 2-deoxy glucose, which by interfering with neuronal glucose metabolism induces a selective neuronal glucopenia $[22,23]$. This means that the substance causes a systemic hyperglycaemia, which in itself usually increases islet blood flow [27]. In our study, however, a decrease in islet blood flow was observed. This supports the notion that hypoglycaemia decreases islet blood flow through nervous mechanisms. However, the drug could have other effects affecting islet blood flow, e.g. by induction of hyperinsulinaemia. To further examine the mechanisms behind the decreased islet blood flow during hypoglycaemia, we studied islet blood flow in both the native and transplanted gland 2 weeks after a whole-pancreas transplantation, i.e. at a time point when the gland is functionally denervated, but when the graft pancreatitis has disappeared [29]. Insulininduced hypoglycaemia decreased islet blood flow on- ly in the native, but not in the transplanted gland. The findings suggest that catecholamines released from the adrenal glands in response to increased sympathetic nervous activity are not likely to be responsible for the changed islet blood flow because the transplanted glands would also have been affected by circulating substances. The possibility that denervation would decrease the sensitivity of the graft to circulating catecholamines is not likely, as its reactivity to other adrenergic substances is unchanged [36]. Furthermore, denervation is more likely to lead to a hypersensitivity of adrenergic receptors [37]. The possible reason for the lack of hypoglycaemia-induced effects on islet blood flow within the transplanted gland is denervation of the gland, and thereby an abolishment of influences from the nervous system.

The exact nature of the nerves involved in the hypoglycaemia-induced islet blood flow decrease is not known. Influence on islet blood flow has been shown to be exerted by vagal [4], sympathetic [3, 6, 33, 38], as well as peptidergic [39] nerves. Activation of all these nervous systems also seems to occur in the pancreas and its islets in response to hypoglycaemia [40].

The GK rat is a non-obese animal model of hereditary Type 2 diabetes mellitus characterised by impaired glucose tolerance and mild hyperglycaemia $[24,25]$. The animals have aberrations in glucose metabolism and stimulus-secretion coupling within the beta cells [41, 42, 43, 44, 45, 46]. Impairment of betacell function, although less pronounced, is also present in the $\mathrm{F}_{1}$-hybrids of GK and Wistar rats [46]. In general, increased functional demands on the pancreatic islets are associated with an islet blood hyperperfusion [1]. In line with this, an increased islet blood flow is seen in Type 2 diabetic GK rats and their $F_{1}$ hybrids, but also disturbances in islet blood flow regulation [10, 11, 13, 47, 48]. The decreased islet blood perfusion that we observed in normal rats in response to hypoglycaemia is theoretically advantageous during hypoglycaemia, as it could reduce the dispersal of insulin to the peripheral circulation, thereby diminishing the degree of hypoglycaemia. Since insulin therapy, frequently also given to lean Type 2 diabetic patients, increases the risk of hypoglycaemic episodes, such defense could be important. We investigated the influence of insulin-induced hypoglycaemia on islet blood perfusion in Type 2 diabetic GK rats. Although neuropathic changes are known to occur in diabetic GK rats $[49,50]$, an even more pronounced decrease in islet blood flow occurred in the GK rats than in normal rats. Of interest, diabetic GK rats and their hybrids have been shown to have an increased islet blood flow during normal conditions dependent on a glucose-dependent mechanism mediated by the vagus nerve [11, 13]. Whether also the more pronounced hypoglycaemia-induced decrease in islet blood flow in GK rats compared to normal rats, relates to changed vagal nervous activity is not known. 
In normal rats, whole pancreatic blood flow was unchanged (Sprague-Dawley, Wistar-Furth) or slightly decreased (Wistar) in response to insulin-induced hypoglycaemia. The former result is consistent with previous findings [14]. In contrast, an increased whole pancreatic blood flow was observed in Sprague-Dawley rats [15]. The reasons for this difference are not known, but could reflect the use of anaesthesia or erroneous measurements when using the repeated microsphere injection approach. Although the decrease was not as substantial as that in islet blood flow, especially GK rats but also their $F_{1}$-hybrids, responded with a pronounced decrease in total pancreatic blood flow to insulin-induced hypoglycaemia. Not only islet blood flow, but also whole pancreatic blood flow, have been observed to depend on an increased vagal nervous activity in GK rats and their F1-hybrids [11, 47].

In our study, the influence of insulin-induced hypoglycaemia on several other abdominal organs than the pancreas was examined in Sprague-Dawley rats. An increased adrenal and arterial hepatic blood flow was seen whereas other regional circulations were not affected. Increased secretion of catecholamines is well known to occur in response to hypoglycaemia [40]. Our study shows that this is related to increased adrenal blood flow. Increased blood flow in the superior mesenteric artery occurs during insulin-induced hypoglycaemia [51].

In conclusion, a consistent finding in our study was the association between hypoglycaemia and a decreased islet blood flow. The nervous system seems to be of crucial importance for this response. From a teleological point of view it can be argued that a decreased islet blood perfusion could be advantageous during hypoglycaemia, since it can reduce the dispersal of insulin to the peripheral circulation, thereby diminishing the degree of hypoglycaemia.

Acknowledgements. The skilled technical assistance of Birgitta Bodin and Astrid Nordin is gratefully acknowledged. Financial support was received from the Swedish Research Council (72X-109, 19X-00034), the Swedish Diabetes Association, the Swedish-American Diabetes Research Program funded by the Juvenile Diabetes Research Foundation and the Wallenberg Foundation, the NOVO Nordic Research Fund, the Swedish Society of Medicine and the Family Ernfors Fund.

\section{References}

1. Jansson L (1994) The regulation of pancreatic islet blood flow. Diabetes Metab Rev 10:407-416

2. Jansson L (1985) Dissociation between pancreatic islet blood flow and insulin release in the rat. Acta Physiol Scand 124:223-228

3. Jansson L, Eizirik DL, Sandler S (1989) Terbutaline decreases the blood perfusion of the pancreatic islets but does not reduce the diabetogenic action of streptozotocin in the rat. Eur J Pharmacol 161:79-83

4. Jansson L, Hellerström C (1986) Glucose-induced changes in the pancreatic islet blood flow mediated by the central nervous system. Am J Physiol Endocrinol Metab 251: E644-E677

5. Carlsson PO, Iwase M, Jansson L (1999) Stimulation of intestinal glucoreceptors in rats increases pancreatic islet blood flow through vagal mechanisms. Am J Physiol Regul Integr Comp Physiol 276:R233-R236

6. Carlsson PO, Iwase M, Jansson L (2000) Intraportal glucose infusion and pancreatic islet blood flow in anesthetized rats. Am J Physiol Regul Integr Comp Physiol 279:R1224-R1229

7. Carlsson PO, Olsson R, Källskog Ö, Bodin B, Andersson A, Jansson L (2002) Glucose-induced islet blood flow increase in rats: interaction between nervous and metabolic mediators. Am J Physiol Endocrinol Metab 283:E457E464

8. Styrud J, Eriksson UJ, Jansson L (1992) A continuous 48-h glucose infusion in rats causes both an acute and a persitent redistribution of the blood flow within the pancreas. Endocrinology 130:2692-2696

9. Atef N, Ktorza A, Picon L, Pénicaud L (1992) Increased islet blood flow in obese rats: role of the autonomic nervous system. Am J Physiol Endocrinol Metab 262:E736-E740

10. Atef N, Portha B, Pénicaud L (1994) Changes in islet blood flow in rats with NIDDM. Diabetologia 37:677-680

11. Svensson AM, Abdel-Halim SM, Efendic S, Jansson L, Östenson C-G (1994) Pancreatic and islet blood flow in F1-hybrids of the non-insulin-dependent diabetic GKWistar rat. Eur J Endocrinol 130:612-616

12. Iwase M, Uchizono Y, Tashiro K, Goto D, Iida M (2002) Islet hyperperfusion during prediabetic phase in OLETF rats, a model of type 2 diabetes. Diabetes 51:2530-2535

13. Carlsson P-O, Jansson L, Östenson C-G, Källskog Ö (1997) Islet capillary blood pressure increase mediated by hyperglycemia in NIDDM GK rats. Diabetes 46:947952

14. Sparrow RA, Beckingham IJ (1989) Islet blood flow following insulin administration. J Anat 163:75-81

15. Iwase M, Tashiro K, Uchizono Y, Goto D, Yoshinari M (2001) Pancreatic islet blood flow in conscious rats during hyperglycemia and hypoglycemia. Am J Physiol Regul Integr Comp Physiol 280:R1601-R1605

16. Vetterlein F, Senske D, Bornkessel C, Schmidt G (1985) Effects of tolbutamide on blood flow in islets and exocrine tissue of the rat pancreas. Eur J Pharmacol 113:395-398

17. Christensen NJ (1983) Acute effects of insulin on cardiovacular function and noradrenaline uptake and release. Diabetologia 25:377-381

18. Baron A (1994) Hemodynamic actions of insulin. Am J Physiol Endocrinol Metab 268:E187-E202

19. Cleland SJ, Petrie JR, Ueda S, Elliott HL, Connell JMC (1998) Insulin as a vascular hormone: implications for the pathophysiology of cardiovascular disease. Clin Exp Pharmacol Physiol 25:175-184

20. Levey GS, Lasseter KC, Palmer RF (1974) Sulfonylureas and the heart. Annu Rev Med 25:69-74

21. Robertson BE, Paterson DJ, Peers C, Nye PCG (1989) Tolbutamide reverses hypoxic pulmonary vasoconstriction in isolated rat lungs. Q J Exp Physiol 74:959-962

22. Hökfelt B, Bygdeman S (1961) Increased adrenaline production following administration of 2-deoxy-D-glucose in the rat. Proc Soc Exp Biol Med 106:537-545

23. Müller EO, Cocchi D, Forni A (1971) A central site for the hyperglycemic action of 2-deoxy-D-glucose in mouse and rat. Life Sci 10:1057-1061

24. Kimura K, Toyota T, Kakizaki M, Kudo M, Takebe K, Goto Y (1982) Impaired insulin secretion in the spontaneous diabetic rat. Tohoku J Exp Med 137:453-459 
25. Goto Y, Suzuki K, Sasaki M, Ono T, Abe S (1988) GK rat as a model of nonobese, noninsulin-dependent diabetes. Selective breeding over 35 generations. In: Shafrir E, Renold AR (eds) Frontiers in diabetes research. Lessons from animal diabetes II. John Libbey, London, pp 301303

26. Suzuki KI, Goto Y, Toyota T (1993) Spontaneously diabetic GK (Goto-Kakizaki) rats. In: Shafrir E (ed.) Lessons from animal diabetes IV. Smith Gordon, London, pp 107-116

27. Jansson L, Hellerström C (1983) Stimulation by glucose of the blood flow to the pancreatic islets of the rat. Diabetologia 25:45-50

28. Jansson L, Hellerström C (1981) A rapid method of visualizing the pancreatic islets for studies of islet capillary blood flow using non-radioactive microspheres. Acta Physiol Scand 113:371-374

29. Jansson L, Korsgren O, Wahlberg J, Andersson A (1992) Pancreatic islet blood flow after syngeneic pancreaticoduodenal transplantation in rats. Transplantation 53:517-521

30. Olausson M, Mjörnstedt L, Lindholm L, Brynger H (1984) Nonsuture organ grafting of the neck vessels in rats. Acta Chir Scand 150:463-466

31. Lifson N, Kramlinger KG, Mayrand RR, Lender EJ (1980) Blood flow to the rabbit pancreas with special reference to the islets of Langerhans. Gastroenterology 79:466-473

32. Iglesias-Barreira V, Ahn MT, Reusens B, Dahri S, Hoet JJ, Remacle C (1996) Pre- and postnatal low protein diet affect pancreatic islet blood flow and insulin release in adult rats. Endocrinology 137:3797-3801

33. Meyer HH, Vetterlein F, Schmidt G, Hasselblatt A (1982) Measurement of islet blood flow in pancreatic islets of the rat. Effect of isoproterenol and norepinephrine. Am J Physiol Endocrinol Metab 242:E298-E304

34. Jansson L, Swenne I (1989) Age-dependent changes of pancreatic islet blood flow in the rat. Int $\mathrm{J}$ Pancreatol 5: 157-163

35. Carlsson PO, Källskog Ö, Bodin B, Andersson A, Jansson L (2002) Evaluation of repeated injections of coloured microspheres for islet blood flow measurements in anaesthetised rats: influence of microsphere size. Ups J Med Sci 107: 111-120

36. Jansson L, Wahlberg J, Andersson A (1993) Differences in the vascular response to terbutaline in the native and transplanted rat pancreas. Eur Surg Res 25:383-389

37. Pipeleers DG, Pipeleers-Marichal MA, Karl IE, Kipnis DM (1978) Secretory capability of islets transplanted intraportally in the diabetic rat. Diabetes 27:817-824

38. Rooth P, Täljedal I-B (1987) Vital microscopy of islet blood flow. Catecholamine effects in normal and ob/ob mice. Am J Physiol Endocrinol Metab 252:E130-E135
39. Carlsson P-O, Sandler S, Jansson L (1996) Influence of the neurotoxin capsaicin on rat pancreatic islets in culture, and on the pancreatic islet blood flow of rats. Eur J Pharmacol 312:75-81

40. Havel PJ, Taborsky Jr GJ (1989) The contribution of the autonomic nervous sytem to changes of glucagon and insulin secretion during hypoglycemic stress. Endocr Rev 10: $332-350$

41. Giroix MH, Vesco L, Portha B (1993) Functional and metabolic perturbations in isolated islets from the GK rat, a genetic model of non-insulin-dependent diabetes. Endocrinology $132: 815-822$

42. Ling ZC, Efendic S, Wibom R et al. (1998) Glucose metabolism in Goto-Kakizaki rat islets. Endocrinology 139: 2670-2675

43. MacDonald MJ, Efendic S, Östenson CG (1996) Normalization by insulin treatment of low mitochondrial glycerol phosphate dehydrogenase and pyruvate carboxylase in pancreatic islets of the GK rat. Diabetologia 45:886-890

44. Östenson CG, Abdel-Halim SM, Rasschaert J et al. (1993) Deficient activity of FAD-linked glycerophosphate dehydrogenase in islets of GK rats. Diabetologia 36:722-726

45. Östenson CG, Khan A, Abdel-Halim SM et al. (1993) Abnormal insulin secretion and glucose metabolism in pancreatic islets from the spontaneously diabetic GK rat. Diabetologia 36:3-8

46. Abdel-Halim SM, Guenifi A, Grill V, Luthman H, Efendic S, Östenson C-G (1994) Impact of diabetic inheritance on glucose tolerance and insulin secretion in spontaneously diabetic GK-Wistar rats. Diabetes 43:281-288

47. Svensson AM, Östenson CG, Sandler S, Efendic S, Jansson $\mathrm{L}$ (1994) Inhibition of nitric oxide synthase by $\mathrm{N}^{\mathrm{G}}$-nitro-Larginine causes a preferential decrease in pancreatic islet blood flow in normal rats and spontaneously diabetic GK rats. Endocrinology 135:849-853

48. Svensson AM, Östenson CG, Jansson L (2000) Age-induced changes in pancreatic islet blood flow: evidence for an impaired regulation in diabetic GK rats. Am J Physiol Endocrinol Metab 279:E1139-E1144

49. Östenson CG, Fière V, Ahmed M et al. (1997) Decreased cortical bone thickness in spontaneously non-insulin dependent diabetic GK rats. J Diabetes Complications 11: 319-322

50. Wada R, Koyama M, Mizukami H, Odaka H, Ikeda H, Yagihashi S (1999) Effects of long-term treatment with alpha-glucosidase inhibitor on the peripheral nerve function and structure in Goto-Kakizaki rats: a genetic model for type 2 diabetes. Diabetes Metab Res Rev 15:332-337

51. Braatvedt GD, Newrick PG, Halliwell M, Wells PNT, Read AE, Corrall RJM (1991) Splanchnic haemodynamic changes during acute hypoglycemia in man. Clin Sci 81:519-524 